\title{
Automated Control Unit of Power Flow in Intellectual Electricity Distribution Network
}

\author{
M.G. Astashev, D.I. Panfilov, P.A. Rashitov, A.N. Rozhkov \\ and D.A. Seregin
}

\begin{abstract}
Results of the development of scientific and technical decisions on creation automated control unit power flow in the intellectual electricity distribution network with microprocessor control system based on modern technologies of design of power electronics devices and digital control systems are presented. Goals and objectives of the study are indicated. Relevance, novelty and practical significance of the work are shown. Properties and opportunities created in the framework of the project equipment are listed.
\end{abstract}

Keywords Power system - Transport capacity flows • Operating modes Transformers $\cdot$ Models $\cdot$ Control system

The concept of smart grid with active-adaptive network requires implementation in power grid wide class of control devices for managing power traffic.

Automated control unit power flow (ACUPF) designed to manage energy flow in an active-adaptive electric smart grid networks. There are more than 10 places in Unified National Electric Grid of Russia where implementation of ACUPF is cost effective.

As a basis for ACUPF building, the project proposed to use the phase-shift device (PSD) with a semiconductor switch. High-speed reliable PSD with a

M.G. Astashev · D.I. Panfilov ( $₫)$ · A.N. Rozhkov

K. A. Krug of JSC "ENIN", Moscow, Russia

e-mail: Panfilov@eninnet.ru

M.G. Astashev

e-mail: Astashev@eninnet.ru

A.N. Rozhkov

e-mail: RozhkovAN@eninnet.ru

P.A. Rashitov · D.A. Seregin

Department of Industrial Electronics, National Research University "Moscow Power

Engineering Institute", Moskva, Russia

e-mail: Rashitov333@mail.ru

D.A. Seregin

e-mail: SereginDA@mpei.ru

(C) The Author(s) 2018

K.V. Anisimov et al. (eds.), Proceedings of the Scientific-Practical Conference

"Research and Development - 2016”, https://doi.org/10.1007/978-3-319-62870-7_17 
semiconductor switch is one of the most technically and economically effective tools for power management in active-adaptive electric networks. PSD with semiconductor switch is not evaluated and implemented so far. The widespread prototypes of PSD are phase-shift transformers with mechanical control devices under the load, have performance with hundreds of times less than the proposed solution in the project. Proposed PSD solution characterized by the original topology and control algorithms of its semiconductor converter, which provide enhanced ACUPF reliability and functionality. The proposed PSD solution, as opposed to the alternative, ensures equality voltage modules at its inputs and outputs, greatly expands the possible range of controlled phase-shift angles and improves its dynamic characteristics.

The aim of the project is ACUPF development with microprocessor control system based on of power electronics devices and digital control systems. ACUPF designed for intellectualization of electric power transmission and distribution process in active-adaptive electric networks and provide high levels of reliability and efficiency of energy transportation and control via power transmission lines.

Major tasks solved in the framework of the project:

- Review of scientific literature and patent search;

- Topology justification of ACUPF;

- Simulation models development of power line with ACUPF location, ACUPF and control system development;

- ACUPF control algorithms development;

- Physical model for the study and debugging ACUPF design;

- Physical model and experimental sample of ACUPF design and manufacturing;

- Physical model and experimental sample of ACUPF evaluation.

The project is the next step for practical realization of active-adaptive power grid. The proposed solution allows to create a world-class technology for the development and implementation of high-speed devices for energy management in power grid with power semiconductor devices and digital control systems.

One of the features of the project is to use Russian components base of power electrical engineering, electronics, and software, which, in turn, contributes to the technological independence of the country in the field of electricity.

In the framework of the project, ACUPF experimental sample was created in conjunction with the physical model of a three-phase power line of $10 \mathrm{kV}$ with a variable phase-shift at the ends of the line. They are unique and can be used for design and evaluation of different ACUPF structures.

The main project results are:

- New methods of ACUPF control;

- Simulation models of ACUPF and power line;

- Proposed approach for simulation and evaluation of ACUPF performance in its specific location in power grid;

- A physical model including experimental sample of ACUPF and power system model (Fig. 1). The model is intended for research and testing of received 
(a)

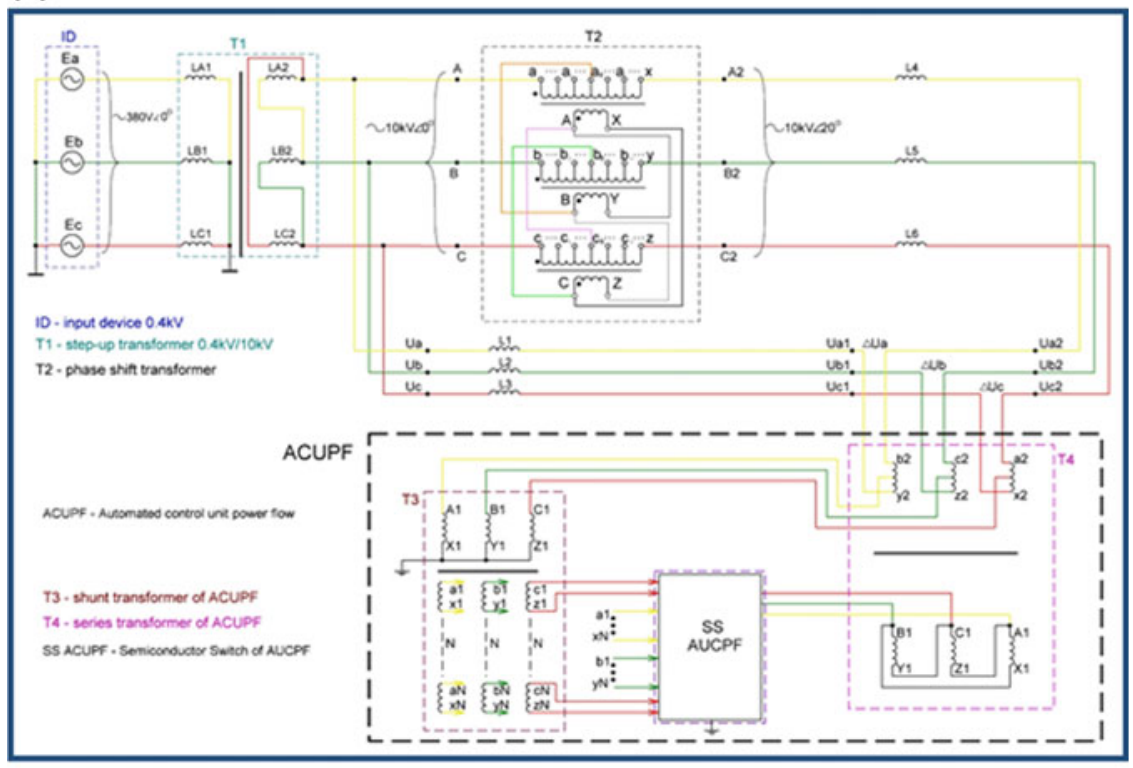

(b)

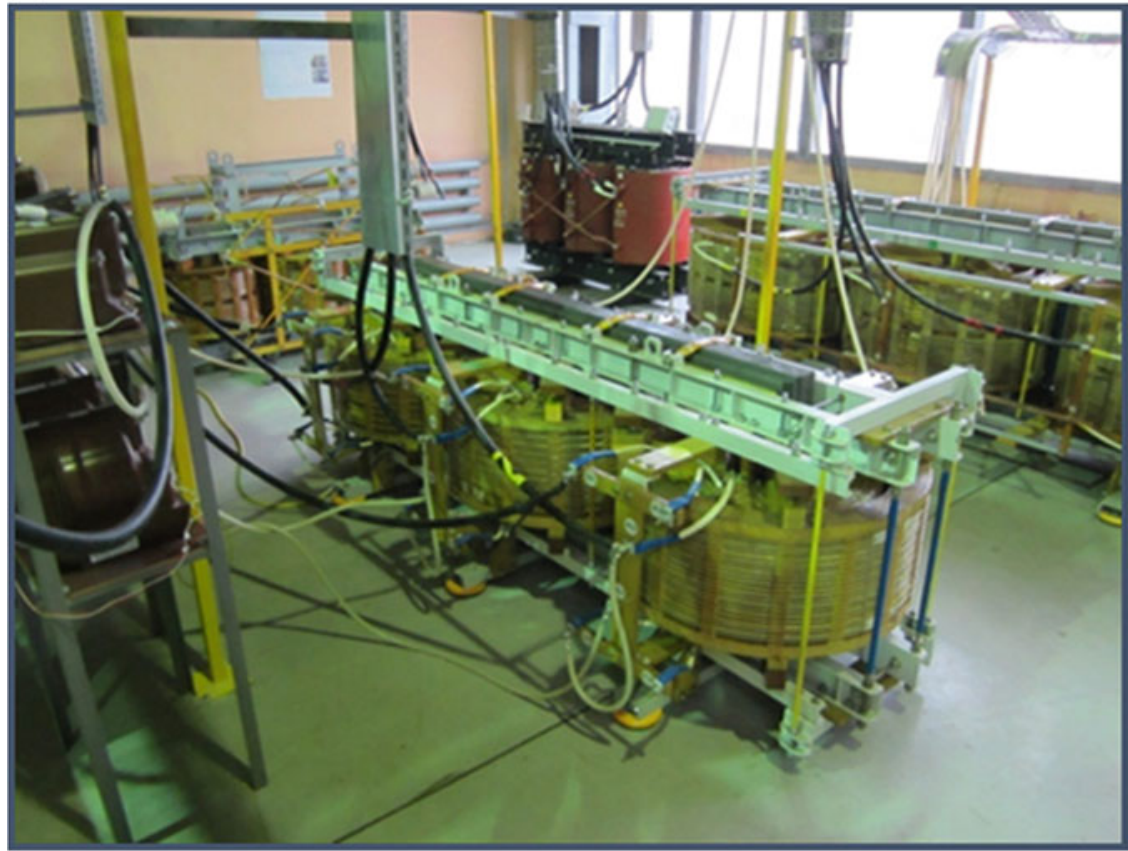

Fig. 1 a Scheme of the physical model and the experimental sample of ACUPF; b Power transformers of physical model and ACUPF; $\mathbf{c}$ The phase of the semiconductor switch of ACUPF; d Compartment of ACUPF control system 
(c)

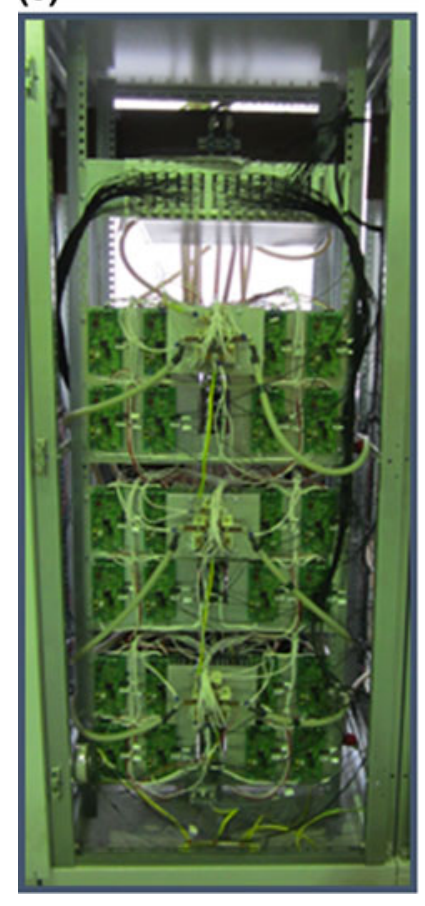

(d)

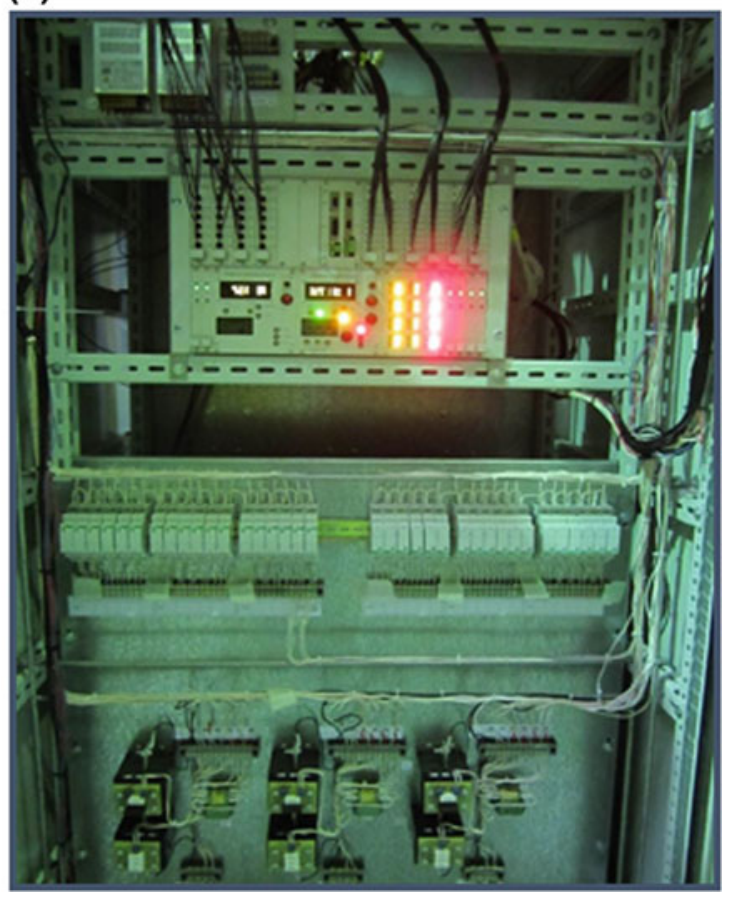

Fig. 1 (continued)

scientific and technical solutions for the intellectualization of electric power transmission and distribution process in the intelligent electrical networks and allows debugging of ACUPF work in various modes;

- Automatic mode control block structure of ACUPF control system that allows adapting to the parameters of the power system operation mode;

- Methods and control algorithms of semiconductor converter as part of ACUPF and algorithms functioning of ACUPF mode automatic control unit;

- Software and hardware of ACUPF digital control system;

- Experimental confirmation of the basic theoretical positions developed in the project.

Participants of the project: one Doctor of Engineering Sciences, four Candidate of Engineering Sciences, as well as the Research Officers and engineers of JSC "ENIN", National Research University "Moscow Power Engineering Institute" and LLC "Togliatti Transformer."

The results of the research: defended one $\mathrm{PhD}$ thesis, one dissertation presented to the defense in December 2016, received two patents [1,2], published eight scientific articles in Russia and abroad [3-10]. 


\section{Conclusions}

1. The effectiveness of automated control unit power flow (ACUPF) with semiconductor switch for power grid modes control had been demonstrated.

2. New algorithms, hardware, and software of ACUPF control system had been developed.

3. ACUPF simulation models had been developed and evaluated.

4. Physical models of power system and ACUPF have been manufactured.

5. Experiments obtained on physical model of power system and ACUPF confirmed the main projects proposals: methods of semiconductor switch control, models of power line, PSD, control system, algorithms, software, and hardware of control system.

6. The guidelines for ACUPF design for its specific location in power grid had been designed.Research are carried out) with the financial support of the Ministry of Education and Science of the Russian Federation. Agreement (contract) no. 14.579.21.0045 26 Aug 2014. Unique project Identifier: RFMEFI57914X0045

\section{References}

1. Panfilov D.I., Novikov A.A., Astashev M.G., Novikov M.A.: The secondary power source. Patent RU №2601419 Issued 01.15.2015 г. (In Russian)

2. Remizevich T.V., Rashitov P.A., Panfilov D.I., Astashev M.G., Novikov M.A., Fedorova M. I., Verbitskaya A.A.: The control system phased switching windings of the shunt transformer of phase shift device. Patent RU №154310 Issued 23.07.2015 г. (In Russian)

3. Astashev M.G., Novikov M.A., Panfilov D.I., Rashitov P.A., Remizevich T.V., Fedorova M. I.: Regarding electrical transmission line's operating modes with controllable phase shifters. Proceedings of the Russian Academy of Sciences. Power Engineering Journal. vol. 1, pp. 1-9 (2016). (In Russian)

4. Astashev M.G., Novikov M.A., Panfilov D.I., Rashitov P.A., Remizevich T.V., Fedorova M. I.: Unbalance mode of traffic flow power control schemes in the intellectual electricity distribution network. Proceedings of the Russian Academy of Sciences. Power Engineering Journal, vol.4, pp. 45-53 (2015). (In Russian)

5. Astashev M.G., Novikov M.A., Panfilov D.I., Rashitov P.A., Fedorova M.I.: A simplified analytical model for the study of unbalance work phase rotation device with a thyristor switch. Proceedings of the Russian Academy of Sciences. Power Engineering Journal, vol.1, pp. 91104 (2015). (In Russian)

6. Astashev, M.G., Novikov, M.A., Panfilov, D.I., Rashitov, P.A., Fedorova, M.I.: Simplified analytical model for open-phase operating mode of thyristor-controlled phase angle regulator. Therm. Eng. 62(13), 928-937 (2015)

7. Voronin P.A., Rashitov P.A., Astashev M.G.: Single-purpose circuitry model thyristor. Electrical engineering Journal, vol.9, pp. 21-30 (2015). (In Russian)

8. Panfilov D.I., Astashev M.G., Rashitov P.A., Rozhkov A.N.: Analysis of key switching methods of AC thyristor bridge. Proceedings of the Russian Academy of Sciences. Power Engineering Journal, vol.4, pp. 148-159 (2014). (In Russian) 
9. Panfilov D.I., Rozhkov A.N., Astashev M.G.: Controlled Phase Shifters Model for Power Grid Operating Modes Calculation. In: IEEE 16 International Conference on Environment and Electrical Engineering. Conference Proceeding, Florence, Italy, 7-10 June 2016, pp 118122

10. Rozhkov A.N., Astashev M.G., Rashitov P.A.: The Influence of Control Methods of AC Thyristor Bridge on its Switching Modes. In: 17th International Conference of Young Specialists on Micro/Nanotechnologies and Electron Devices. Proceedings. Erlagol, Altai, 30 June-4 July 2016, pp. 544-548

Open Access This chapter is licensed under the terms of the Creative Commons Attribution 4.0 International License (http://creativecommons.org/licenses/by/4.0/), which permits use, sharing, adaptation, distribution and reproduction in any medium or format, as long as you give appropriate credit to the original author(s) and the source, provide a link to the Creative Commons license and indicate if changes were made.

The images or other third party material in this chapter are included in the chapter's Creative Commons license, unless indicated otherwise in a credit line to the material. If material is not included in the chapter's Creative Commons license and your intended use is not permitted by statutory regulation or exceeds the permitted use, you will need to obtain permission directly from the copyright holder. 